symptom would cause death and no manoeuvres were employed to prevent penile and testicular "loss".

The most likely explanation for these koro-like symptoms is that of depersonalisation focussing on the genital area, occurring in a state of extreme anxiety. The growing number of cases being reported in non-Chinese subjects, and the strong link with anxiety and anxiety-related states in these cases suggests strongly that these symptoms can be regarded simply as an unusual presentation of anxiety.

Institute of Psychiatry

P. MoOdLey

London SE5

\section{RELAXATION AND DEPERSONALISATION} DEAR SIR,

In his letter (Journal August 1984, 145, 217) Dr Fewtrell noted paradoxical anxiety reactions in seven of forty cases treated with relaxation training. $\mathrm{He}$ also noted a relationship between liability to depersonalisation and negative reactions to relaxation treatment in these patients, and as a result hypothesised that a tendency toward depersonalisation may predispose a patient to respond poorly to progressive relaxation. This hypothesis raises a number of issues.

It seems questionable whether depersonalisation or any other specific negative reaction necessarily confounds the entire relaxation training process. In fact, in their progressive relaxation training manual Bernstein and Borkovec (1973) note a variety of untoward responses to relaxation that might be eliminated by means of a number of specific treatment measures. Specifically they suggest such procedures as therapist modeling, emphasising the patient's self-control, allowing the patient to practice with eyes open, slowing the pace of treatment and general explanation of the negative reactions themselves. Since it is unclear from Dr Fewtrell's report whether such measures were attempted, it remains open to question whether patients' depersonalisation reactions to relaxation can be effectively addressed. My clinical experience has suggested that depersonalisation can be effectively eliminated in some patients by means of the Bernstein and Borkovec (1973) procedures.

However, I do not intend to suggest that all negative responses to relaxation training can be effectively addressed. A recent survey (Edinger \& Jacobsen, 1982) revealed that adverse reactions to relaxation training led to noncompliance or patientinitiated termination of treatment in $3.47 \%$ of the cases treated by a group of 116 clinician respondents. Further these clinicians reported discontinu- ing relaxation training in $3.83 \%$ of their cases because adverse reactions seriously confounded the treatment process. Hence significant treatment confounding reactions to relaxation training seem to be reasonably common.

In addition it is important to note that untoward responses other than depersonalisation can at times confound relaxation treatments. Dr R. Jacobsen and I (Jacobsen \& Edinger 1982), for example, described at length two cases, one with heightened anxiety without depersonalisation and the other muscle cramping. It was interesting that in both cases underlying psychodynamic issues seemed to explain the observed reactions. Moreover, efforts to counteract these reactions failed to eliminate them. Hence, untoward reactions other than depersonalisation require our attention.

JACK D. EDINGER

Veterans Administration Medical Center Durham, North Carolina

\section{References}

Bernsiein. D. A. \& Borkovec. T. D. (1973) Progressive Relaxation Training: A Manual for the Helping Professions. Champaign Illinois: Rescarch Press.

Edinger. J. D. \& JaCOBSEN. R. (1982) Incidence and significance of relaxation treatment side effects. The Behavior Therapist. 5 , 137-138.

FEwireLL. W. D. (1984) Relaxation and depersonalization. The British Journal of Psichiatry. 145, 217.

JACOBSEN. R. \& EDINGer. J. D. (1982) Side effects of relaxation treatment. The American Journal of Psychiatry. 139. 952-953.

\section{DEPRESSION AND PHARMACOLOGICAL TREATMENT}

DEAR SiR,

The recent report by Garvey et al (Journal, 145, October 1984, 363-365) lends support to the notion that stressful life events may precipitate a depression of such severity that pharmacotherapy is warranted. Unfortunately their conclusions would seem to be limited by the patient population's low pre-treatment scores on the Hamilton Rating Scale for Depression (mean-17 \pm 6 ). As they note, their patients might have improved without treatment, in time, or with other, nonsomatic therapies.

An interesting issue not addressed in their data relates to whether the reported stresses were confined to the pre-treatment period or persisted through the treatment period. There has been very little research on the efficacy of pharmacotherapy in Major Depressive Disorder (MDD) in the face of ongoing, stressful life events (Feinberg \& Halbreich, 1985). Existing evidence suggests in fact that some stressors do interfere with the somatic treatment of MMD (Lloyd, 1981; Akiskal, 1982). 
The inclusion of data relevant to this question would have added important information on the interaction of medication and life events in MMD.

\section{References}

AkISKal. H. S. (1982) Factors associated with incomplete recovery in primary depressive illness. Journal of Clinical Psychiatry. 43, 266-271.

Feinberci. S. S. \& Halbreich. U. (1985) Treatment Resistant Depression. Part I. Evaluating the Patient. Drug Therapy. (In Press).

Llord. C.. Zisook. S., Click. M. \& Jaffe. K. E. (1981) Life events and response to antidepressants. Journal of Human Siress. 7, 2-15

Albert Einstein College of Medicine

Shalom Feinberg

Bronx Psychiatric Center

1500 Waters Place

Bronx, N.Y. 10461

\section{EVALUATION OF DAY HOSPITALS}

DeAR SiR,

It would appear that Dr Milne has made a methodological error in his comparison of the outcome of attendance at two psychiatric day hospitals (Journal, 1984, 145, 533-537). He states that "the results indicated that although both day hospitals were serving similar patient samples, only one was achieving significant clinical improvement". In fact the two samples are dissimilar in a fundamental way: at one day hospital he has looked at changes occurring over 3 months to a series of consecutive referrals, at the other he has investigated a series of current attenders who will already have been at the day hospital for some time.

Thus any differences between the outcomes seen at two hospitals could be put down to the fact that those studied in the first hospital were recovering from acute exacerbations of their disorders, whilst those assessed at the second hospital represented a group with continuing morbidity.
The evaluative literature on day care is not sparse (Wilkinson 1984) although depressingly few papers take adequate account of the process variable of the day hospitals studied. A notable exception is Linn (1979). This multicentre controlled trial of day care versus outpatient care of chronic schizophrenic men maintained on antipsychotic medication indicated that day hospitals improved social functioning, but only certain centres were superior in controlling symptoms and preventing relapse. For this population the good results centres placed emphasis on occupational and recreational therapies as opposed to group and family therapies. Poor result centres had a rapid patient turnover and more staff hours worked by psychologists and social workers.

As a separate point Dr Milne is surely correct in underlining the neurotic morbidity of day hospital attenders. Schizophrenics experience considerable neurotic morbidity (McCreadie 1982) and an enquiry into neurotic symptoms should be part of their regular assessment. However day care cannot be recommended for the generality of patients suffering from neurotic illness (Tyrer \& Remington 1979), even "phobic anxiety states".

King's College Hospital

Frank Holloway

Denmark Hill

London SE5 9RS

\section{References}

Linn. M. W., Caffrey, E. M., Klett, J., Hogarty, G. E. \& Lamb, H. R. (1979) Day treatment and psychotropic drugs in the after care of schizophrenic patients. Archives of General Psychiatry. 36, 1055-1066.

MCCreadie. R. G. (1982) The Nithsdale schizophrenia survey I Psychiatric and social handicaps. British Journal of Psychiatry. $140,582-586$

Tyrer, P. J. \& Remington, M. (1979) Controlled comparison of day hospital and outpatient treatment of neurotic disorders. Lancet, $i, 1014-1016$.

WILKINSON, G. (1984) Day care for patients with psychiatric disorder. British Medical Journal, 288, 1710-1711. 